\title{
Analysis on the Competitive Factors of Cultural Industry in Shaanxi Province
}

\author{
Liqin $\mathrm{Li}^{1, \mathrm{a}}$ \\ ${ }^{1}$ Xi'an International University, Xi'an, Shaanxi, 710077 \\ a email
}

Keywords: Cultural Industry; Competitiveness; Key Elements

\begin{abstract}
Shaanxi has rich cultural resources, but the overall competitiveness of Shaanxi cultural industry is not strong. From the "cultural resources", "cultural consumption", "cultural potential", "cultural environment" to analyze the four aspects of Shaanxi cultural industries to influence the competitiveness of the key elements, and finally from the "strengthening the basic competitiveness", " Force "," enhance the environmental competitiveness "and so on to raise the competitiveness of Shaanxi cultural industry countermeasures.
\end{abstract}

\section{Introduction}

Cultural industry is an important way to meet the diverse spiritual and cultural needs of the people. It is an important point to promote the adjustment of economic structure and change the mode of economic development. Especially, under the new economic norm, it is the new growth point of China's economy. At present, the development of cultural industry in Shaanxi Province faces opportunities and challenges. On the one hand, Shaanxi has rich cultural resources, such as the red revolutionary cultural resources in northern Shaanxi, Zhou Qin, Han and other historical and cultural resources and Huashan and other natural scenery resources, at the same time in the publishing, film and television also have strong strength in recent years, the cultural industry health Upward good momentum, is becoming an important engine to promote cultural prosperity. On the other hand, the overall competitiveness of Shaanxi cultural industry is not strong, ranked 16th in the country. On the competitiveness of cultural industries in Shaanxi Province, scholars have carried out a lot of research, but more for the overall level of competitiveness evaluation, failed to really explore the impact of Shaanxi Province, the competitiveness of cultural industries, a key factor. In order to understand the real situation of the development of cultural industry in Shaanxi Province and evaluate the competitiveness of Shaanxi cultural industry objectively, we must analyze the elements of Shaanxi cultural industry competitiveness and lay the foundation for enhancing the competitiveness of cultural industry.

The research shows that "cultural resources", "cultural consumption", "cultural potential" and "cultural environment" are the main factors influencing the competitiveness of a regional cultural industry. Therefore, in order to improve the competitiveness of the cultural industries in the region, it is necessary to enrich the cultural resources and enhance the consumption of cultural products in a certain environment, put in the appropriate human and material resources, develop the cultural and creative industries, so as to improve the regional economy benefit.

\section{Shaanxi Cultural Industry Competitiveness of the Elements of the Rankings}

According to factor analysis, the various factors of cultural industries and comprehensive competitiveness of the various regions are as shown in Table 1. 
Table 1 Ranking of the Competitiveness of Cultural Industry in Provinces and Cities

\begin{tabular}{|c|c|c|c|c|c|}
\hline area & $\begin{array}{l}\text { Cultural } \\
\text { resources }\end{array}$ & $\begin{array}{l}\text { Cultural } \\
\text { consumption }\end{array}$ & \begin{tabular}{|l|} 
Cultural \\
potential
\end{tabular} & $\begin{array}{l}\text { cultural } \\
\text { environment }\end{array}$ & $\begin{array}{l}\text { Comprehensive } \\
\text { Competitiveness }\end{array}$ \\
\hline Guangdong & 1 & 4 & 26 & 1 & 1 \\
\hline Shanghai & 7 & 1 & 5 & 28 & 6 \\
\hline Beijing & 3 & 3 & 18 & 9 & 4 \\
\hline Zhejiang & 5 & 2 & 21 & 2 & 5 \\
\hline Shandong & 2 & 8 & 22 & 6 & 3 \\
\hline Jiangsu & 4 & 5 & 7 & 3 & 2 \\
\hline Hebei & 10 & 10 & 6 & 5 & 10 \\
\hline Hubei & 8 & 9 & 17 & 11 & 14 \\
\hline Fujian & 13 & 7 & 8 & 7 & 8 \\
\hline Hunan & 9 & 16 & 3 & 8 & 9 \\
\hline Henan & 6 & 25 & 12 & 4 & 13 \\
\hline Sichuan & 14 & 24 & 2 & 14 & 7 \\
\hline Anhui & 11 & 12 & 15 & 18 & 11 \\
\hline Shaanxi & 16 & 14 & 11 & 12 & 16 \\
\hline Shanxi & 15 & 13 & 19 & 15 & 25 \\
\hline Liaoning & 25 & 15 & 4 & 19 & 23 \\
\hline Tianjin & 23 & 6 & 23 & 24 & 15 \\
\hline Chongqing & 20 & 17 & 10 & 13 & 22 \\
\hline Jiangxi & 18 & 23 & 9 & 26 & 19 \\
\hline Guangxi & 17 & 21 & 14 & 27 & 21 \\
\hline Yunnan & 12 & 26 & 1 & 10 & 12 \\
\hline Neimenguo & 24 & 11 & 24 & 16 & 20 \\
\hline Jiling & 21 & 19 & 13 & 17 & 17 \\
\hline Xinjiang & 26 & 18 & 28 & 21 & 30 \\
\hline Heilongjiang & 19 & 27 & 25 & 30 & 18 \\
\hline Gansu & 27 & 28 & 16 & 20 & 27 \\
\hline Hainan & 29 & 22 & 27 & 25 & 26 \\
\hline Guizou & 22 & 20 & 31 & 22 & 24 \\
\hline Ningxia & 31 & 29 & 20 & 29 & 28 \\
\hline Qinghai & 28 & 31 & 29 & 23 & 29 \\
\hline Tibet & 30 & 30 & 30 & 31 & 31 \\
\hline
\end{tabular}

From Table 1 we can see that the comprehensive competitiveness of cultural industries in Shaanxi Province ranked 16th in the country, slightly lower than the national average. From the various factors, "cultural resources" and "cultural consumption" rankings in the 16th, slightly lower than the national average; "cultural potential" ranked 11th, higher than the national average; "cultural environment" ranking 12th, higher than the national average.

\section{Competitive Factor Analysis}

Shaanxi Province has a rich cultural resources, why its "cultural resources" ranked only 16th? In 2012, the total investment of cultural institutions in Shaanxi Province accounted for $32.13 \%$ of the total investment, $2.12 \%$ of the local cultural and financial expenditure, $3.71 \%$ of the total number of libraries and museums, $1.59 \%$ of the performing arts groups and $2.76 \%$ of the cultural expenses. From the see, Shaanxi Province, the development of cultural resources is not enough to attract capital capacity is not strong, coupled with weak government support, making the cultural industry resource advantages failed to play well. 
Shaanxi's "cultural consumption factor" ranked 14th, Shaanxi Province, the cultural consumption demand is not high, including Shanghai scoring reached 3.63, Zhejiang, Guangdong and Beijing scores are more than 1.2, in the forefront are cultural consumption The concept of newer and cultural spending capacity of the region, but also the more developed areas of the economy. In recent years, the economy of Shaanxi Province shows a rapid growth momentum, but the Shaanxi Province population base is relatively large, and the per capita income level only reached the domestic level. Which led to the consumer demand for cultural products is not high. On the other hand, the supply of cultural market in Shaanxi Province is not balanced, failed to meet the rural residents of cultural products. The study found that urban and rural residents in Shaanxi Province, cultural consumption, mainly watching TV, listening to radio and Internet and other types. Among them, $70 \%$ of the family for cultural consumption expenditure accounted for only 5\% of the total annual income, urban and rural cultural consumption there is a big gap. Fortunately, in recent years, Shaanxi Province, cultural consumption demand was increasing year by year trend, as shown in Figure 1.

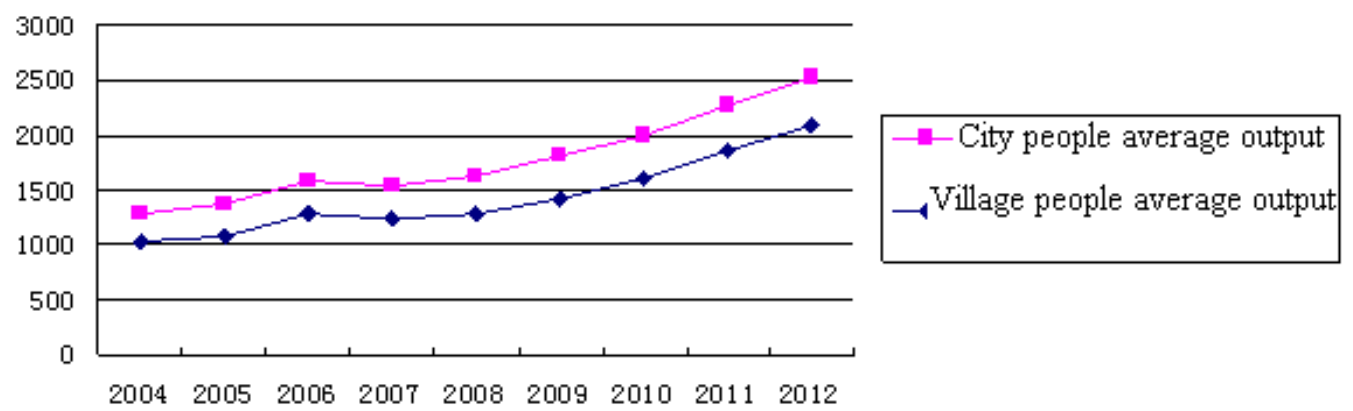

Figure 1 Per capita cultural consumption of residents in Shaanxi Province

Shaanxi Province, "cultural potential factor" ranked 11th, indicating that the cultural industry in Shaanxi Province, there is a certain competitive potential, the future can maintain a good momentum of development. Constitute the main factor of the composition of the total number of foreign tourists, tourism, foreign exchange earnings, cultural and creative industries, the number of industrial parks, reflecting the region's cultural industry development potential. Shaanxi Province and the western region of Yunnan, Sichuan, there are still some gaps.

Shaanxi 's "cultural environment factor" ranked 12th in the country. Shaanxi Province since 2007, the cultural industry has maintained a rapid growth rate, the rapid development. However, according to Figure 2 comparison, although the size of the cultural market in Shaanxi Province ranked 12th in the country, but the factor score found that the overall competitiveness of the cultural environment in Shaanxi Province is far below the top five areas, and with the subsequent Of the Sichuan and Chongqing scoring only a weak gap, indicating that the scale of Shaanxi Province in the cultural industry, industrial efficiency and related industries on the development is still relatively backward, the future should be bigger and stronger Shaanxi Province cultural industry, and actively develop new cultural industries.

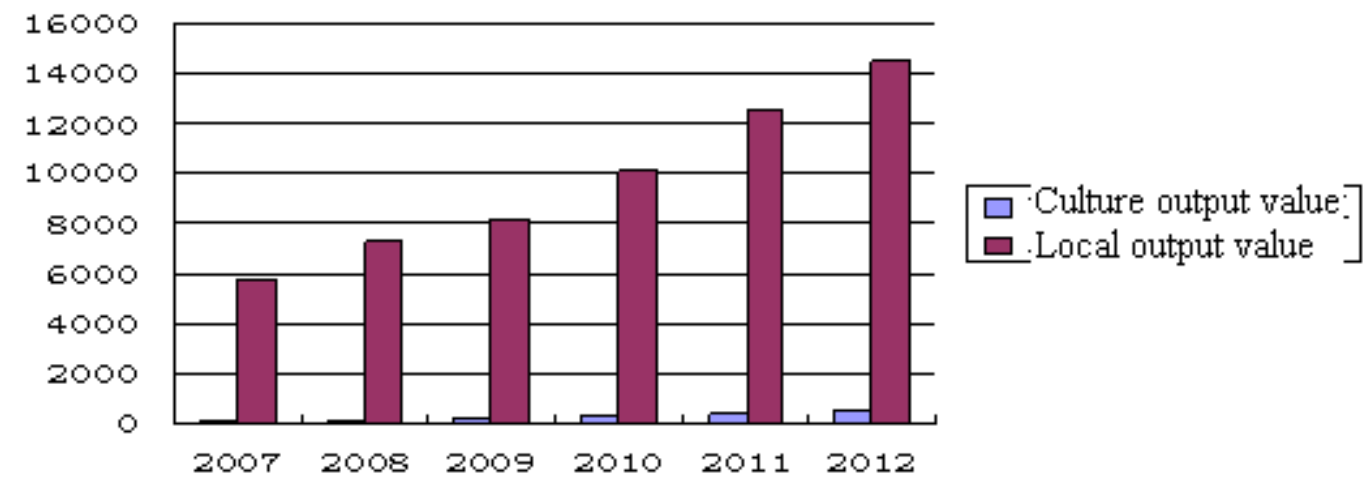

Figure 2 Shaanxi Province cultural industry scale 


\section{Countermeasures to Enhance the Competitiveness of Cultural Industries in Shaanxi Province}

Shaanxi Province, the overall competitiveness of cultural industries is not strong, cultural resources, cultural consumption, cultural potential, cultural environment and other key elements of the development efforts are not the most fundamental reason. At the same time, the economic strength of Shaanxi has affected the competitiveness of its cultural industry to a certain extent, resulting in the lack of complete facilities supporting the cultural industry, lack of innovation in product design, lack of consumer awareness and imperfect policies. Therefore, Shaanxi Province should seriously study and solve the above problems, and actively introduce social capital to participate in the construction of cultural industries, to meet consumer demand, optimize the market environment and market structure, create a cultural brand with characteristics in Shaanxi Province, enhance industrial advantages, improve the cultural industry in Shaanxi Province Competitiveness.

Shaanxi Province has a large number of libraries, museums and art galleries and other basic resources, but the development and utilization of efforts is not enough. It is recommended to its full development and utilization, to provide residents with rich cultural products. In the city can build more experience of cultural square and exhibition hall. At the same time to strengthen the construction of rural cultural facilities.

Analysis found that Shaanxi only tourism and publishing industry has a slight advantage, the competitiveness of other industries is weak, the industry scale is not large. Therefore, the cultural tourism industry in Shaanxi Province should be the center point, vigorously develop cultural tourism, to enhance the competitiveness of cultural industries in Shaanxi Province. Shaanxi has a profound cultural heritage, can build a "cultural - cultural relics - tourism" a combination of tourism industry, focusing on cultural characteristics, the depth of the development of tourism resources, enhance the cultural taste of tourism products. Such as the rich natural resources of the Qinling Mountains, known as the "North-South plant blend, north and south biological species library" reputation, through the landscape culture as the main tourist, to create national forest park; Shaanxi red historical and cultural resources, can Yanan as the center, Tourism routes, the red revolutionary culture theme, and the Loess Plateau folk combination. But also to create the southern Shaanxi area of the "Three Kingdoms" culture, more in-depth development of Huaqing pool, Drum Tower and other historical resources, Huashan, Lishan and other natural landscape cultural tourism potential, play the attractiveness of history and culture, thus driving the competition in Shaanxi Province force.

To create a good cultural industry development environment, the cultural industry plays a vital role, so the gathering area is an important space carrier. Shaanxi should build a number of unique cultural gathering area, you can use the market model, the first introduction of the industry's leading enterprises, and then develop a gathering area development strategy, and finally actively lobbying international well-known enterprises to join, the formation of industrial chain. Qujiang Industrial Park to the most representative, through the integration of resources, and vigorously promote the intensive and efficient way of cultural industry development, to explore a unique cultural industry economic model. Through the Qujiang model, the province's cultural industry play a leading role in promoting the cultural industry value, and strengthen the cultural industry in Shaanxi Province.

(1) vigorously develop the cultural theme of the park. To the Yellow Emperor Mausoleum and the Yandi Mausoleum as the main body, to build Huaxia ancestor Park; to Terracotta Warriors and Tombs and Qin Shi Huang as the main body of the Qin culture, the development of Qin culture park; Qujiang as the main Tang cultural park; to Baoji Famen Temple as the basis, Campus; it can build Shaanxi University students cultural and creative industrial park, to stimulate the potential of college students to encourage students to set up cultural industries and enterprises, and so on the Shaanxi cultural industrial park.

(2) to create a modern industrial base. To create an animation creative base to Xi'an Software Park and high-tech zones as the main body, and vigorously develop the Shaanxi animation industry; to create Shaanxi cultural relics imitation industry base, high-end cultural relics as a re-engraved objects, the province's complex enterprises Value-added, high-grade development direction, thus 
establishing the country's largest high-end cultural relics engraved trading market.

(3) to Xi'an Economic and Technological Development Zone as the main printing and packaging industry base, the establishment of innovative design, development and production, marketing display as one of the western first-class printing and packaging industry demonstration park.

From the factor analysis found that the spending power factor score lower than the national level. While the per capita GDP and disposable income of Shaanxi Province in the country must affect the consumption of cultural products, such as high medical care, education costs and higher prices. There is a well-known American economist Franco Modigliani, put forward the cycle of consumption theory, that people will consider the future consumption of uncertain factors will not cause trouble to life, so will be part of the income as a contingency fund, which will The impact is the consumption of expenditure, especially those more flexible consumer products. It can be seen from Figure 3, rural residents in the cultural consumption expenditure and the gap between urban residents is very large, so how to enhance the rural residents' consumption concept has a huge space.

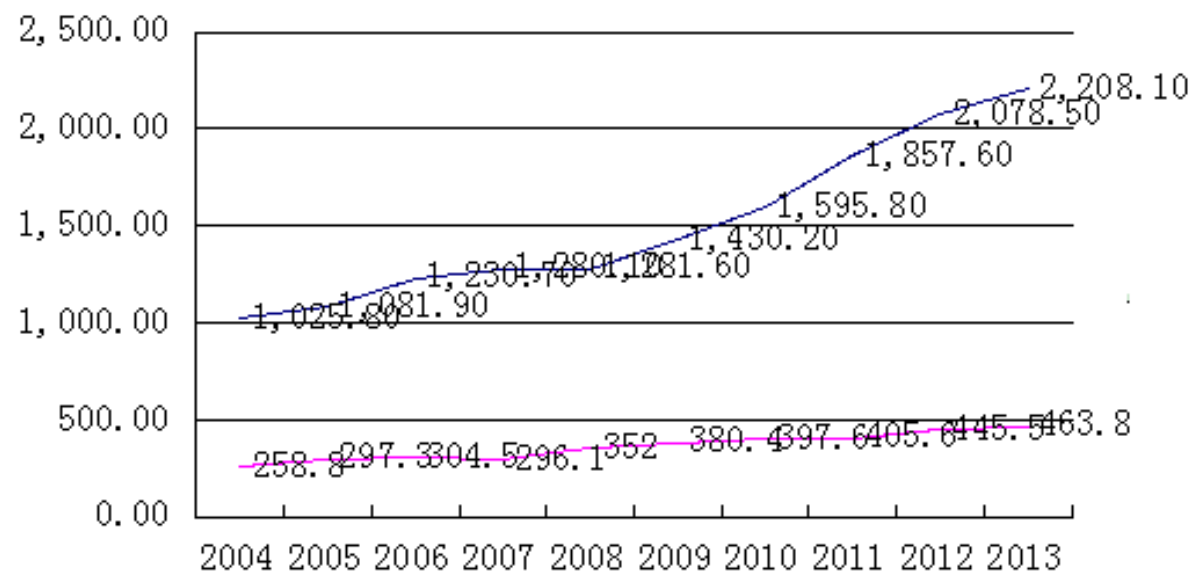

Fig 3. Comparison of per capita cultural consumption expenditure of rural residents in cities and towns in 2004-2013

Stimulate the residents of the cultural concept of consumer goods, first of all to start from the income. Only to improve the income level of residents, especially in low-income people in order to better stimulate people's consumption of cultural products; second is to enhance the cultural literacy of residents to improve their interest in cultural products, cultivate the correct concept of cultural consumption; Is to rural areas, to increase the urban and rural interactive effect, to ensure that does not affect the rural ecological environment under the conditions of mining rural cultural resources, making the rural and urban cultural industries combined to make full use of rural cultural consumption resources. And ultimately stimulate the residents of the consumption of cultural products concept.

Shaanxi Province, there are common problems in the cultural enterprises, smaller, lack of well-known cultural enterprises. The core competitiveness of an enterprise is reflected in the existence of the company's own brand value. Such as the more well-known international cultural enterprises: Hollywood and Disney, so only from the brand strategy to form the core competitiveness of enterprises, you can set up a brand of funds, when an enterprise in the brand effect on the results, to reward, Which can stimulate the innovation of other enterprises.

Shaanxi Province at this stage there are six cultural brands, we can vigorously develop the cultural characteristics of Shaanxi brand. Give full play to Shaanxi rich historical and cultural resources, such as Yan'an's red history and culture, Qin and Han Tang under the background of the historical and cultural brand; Shaanxi also has a wide range of folk culture. Such as to be classified as intangible cultural heritage of the Qin cavity, folk songs in northern Shaanxi, Ansai drums, paper cutting and other folk culture; to Huashan, Zhongnanshan, Taibai Mountain and other natural landscape culture brand. In this area the western region of Yunnan, it is to do more outstanding, the development of a national characteristics of the industry, to create a brand with Yunnan characteristics. To the national song and dance, cultural tourism, folk art and rural culture as a basis 
for the combination of reasonable planning, is the full use of cultural resources. It is held in the country cultural exchange activities and art exhibition, and the country to build a full display of the most representative of Yunnan folk Sanni embroidery and "Yunnan impression" platform. Shaanxi should learn from the successful experience of Yunnan, to create a Northwest cultural brand, and comprehensively enhance the core competitiveness of Shaanxi Province.

Enterprise innovation ability, on the one hand from the excellent talent, on the other hand this is the investment of scientific research. The key to the development of cultural enterprises lies in the excellent management and service personnel, Beijing's concert hall, Shenzhen's "Splendid China" are successful examples. Shaanxi Province in this area is extremely scarce talent, so to establish a wide range of personnel training mechanism, you can introduce domestic and foreign outstanding cultural industry team or management personnel, improve the cultural industry practitioners of the overall quality and ability. The establishment of salary awards punishment, to encourage outstanding staff. As for the investment in scientific research, the government should first support and help the cultural enterprises, from a technical point of view, you can create a technical service platform to provide more digital development support. The government will support the development of the cultural industry associations, clarify the functions of the government, transfer the evaluation work to the trade associations, and relax the conditions for the overseas capital to enter the market. At the same time, the government will support the development of the cultural industry associations, Actively attracting overseas capital and social capital, to stimulate the vitality of cultural enterprises, with the help of the government to completely release the potential of cultural innovation in Shaanxi Province, so as to quickly promote the cultural industry innovation and development.

Shaanxi Province in 2009 for the cultural industry's financial expenditure of 9.181 billion yuan, ranked seventh in the country, but only the total expenditure of $2.76 \%$ of Shaanxi Province, ranked 13th in the country, indicating that Shaanxi Province for the cultural industry investment With the current economic rankings do not match. The government should give full play to the functions and play an important role in promoting the development of cultural industries. So the Shaanxi provincial government should increase the financial strength of the cultural industry.

First of all, the government should deal with the tax relief policies of cultural industries such as publishing and printing, public welfare cultural performances and radio, as well as non-profit industries such as libraries and museums, and to take tax exemption when purchasing literature and equipment. Finally, to encourage social capital to invest in cultural enterprises, the government should actively encourage and support social funds for the construction of some cultural facilities. But the government's support is to be limited, can not undermine the market mechanism, affecting the stable development of cultural markets. Therefore, the encouragement and support of the enterprise financial funds, can not make enterprises over their dependence on the psychological, leading to the lack of independent innovation enterprises, should be market-driven, the government in the implementation of supporting enterprises to support the function, The principle of public nature, timely financial support to enterprises, making the government's financial support to fully play its functions.

Although the government's financial subsidies have an important role, but these funds are not enough to make the rapid development of cultural enterprises. Effective investment and financing system can promote the development of enterprises faster and stronger. The government can create a cultural investment company, some of the momentum of the development of small companies to invest, you can take the way to give financial support. For the construction of large cultural projects, we can attract foreign investment to participate in, especially some foreign outstanding cultural enterprises, not only can better complete the project construction, improve project development efficiency and economic benefits, at the same time can also learn its advanced Experience technology. For those excellent cultural enterprises, to promote its listing and find bonds, the cultural industry and financial markets together, not only to absorb social funds can also promote the enterprise more perfect and healthy development. But also to encourage private capital to enter the cultural industry market, the Government appropriate to relax the inflow criteria, and jointly 
promote the rapid development of cultural industries.

\section{References}

[1] Xie Luncan. To enhance the accuracy and scientific nature of China's cultural industry statistics [J], academic exchanges, 2009 (12)

[2] Li Chong. Research on Evaluation of Cultural Industry Competitiveness in Shaanxi Province [D]. Xi'an University of Technology, 2015

[3] Zhan Shaowen, Xin Wu Chao. Journal of Jishou University Journal of Jishou University, 2012 (9)

[4] Bi Xiaoqing, Wang Daili. The Progress, Problems and Prospects of the Research on the Competitiveness of Cultural Industry [J], Technology Economics and Management Research, 2009 (5)

[5] Wang Wenfeng, Xu Xiaoli. Study on the Determinants and Index System of Competitiveness of Regional Cultural Industry [J], China Cultural Industry Review, 2014 (7)

[6] Wang Lan, Zhao Guojie. Based on ANP's regional cultural industry competitiveness evaluation model and index system [J], Science and Science and Technology Management, 2008 (7) 